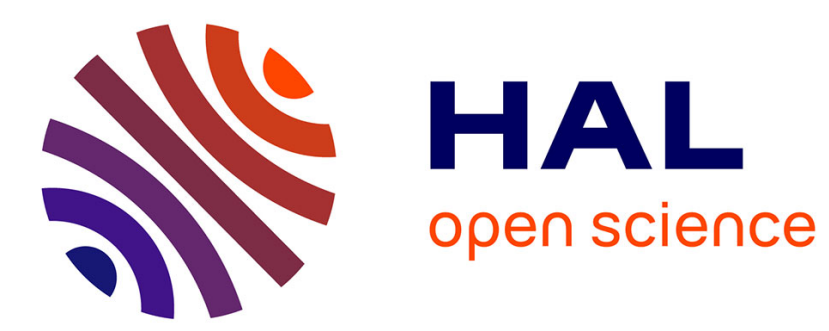

\title{
Modelling of Precursor Flow and Deposition in Atomic Layer Deposition Reactor
}

\author{
H. Siimon, J. Aarik
}

\section{To cite this version:}

H. Siimon, J. Aarik. Modelling of Precursor Flow and Deposition in Atomic Layer Deposition Reactor. Journal de Physique IV Proceedings, 1995, 05 (C5), pp.C5-245-C5-252. 10.1051/jphyscol:1995528 . jpa-00253853

\section{HAL Id: jpa-00253853 https://hal.science/jpa-00253853}

Submitted on 1 Jan 1995

HAL is a multi-disciplinary open access archive for the deposit and dissemination of scientific research documents, whether they are published or not. The documents may come from teaching and research institutions in France or abroad, or from public or private research centers.
L'archive ouverte pluridisciplinaire HAL, est destinée au dépôt et à la diffusion de documents scientifiques de niveau recherche, publiés ou non, émanant des établissements d'enseignement et de recherche français ou étrangers, des laboratoires publics ou privés. 


\title{
Modelling of Precursor Flow and Deposition in Atomic Layer Deposition Reactor
}

\author{
H. Siimon and J. Aarik
}

University of Tartu, Institute of Experimental Physics and Technology, Ülikooli 18, EE2400 Tartu, Estonia

\begin{abstract}
Lambda$ calculation model to study alomic layer deposition $(\Lambda \mathrm{I}, \mathrm{D})$ in low-pressure channel-type $C V I)$ reaclor with many parallel substrates is described. 'The calculations are based on continuity equation and kinetic equation for surface coverage. I"ormation of a steady-state adsorption wave propagating between the substrates during a precursor pulse is studied. I ho effect of diffusion and sticking coefficients, carrier gas flow rate and growth t.cmperature on formation and propagation of the steady-state adsorption wave is analyzed.
\end{abstract}

\section{INTRODUCTION}

Atomic layer deposition (A.LD) - the technique at which the different constituent clements of a solicl compound are deposited during alternate precursors pulses, allows to obtain thin film structures of high quality. In addition to the possibility to grow uniform films on profiled substrates and unique multilayer structures, ALD has demonstrated to be a proper technique for characterization of the growth kinctics and evaluation of the quantities related to that.

The experimental methods used for investigation of the growth kinctics in chemical vapor deposition (CVD) and ALD equipment include optical methods [1-5], mass spectrometry [5-7], spectro-cllipsometry [8], deposit mass moniforing by guartz microbalance [9-1I] and gravimetry [12]. Data about the gas phase consistency of the surface coverage are obtained from these measurements. Furthermore, comparing the data to some theoretical model, the quantitics characterizing surface (or gas phase) reactions can be calculated.

Propagation of precursors and film growth in low-pressure CVD equipment has been investigated using various computational models, c.g. [13-16]. However, the models are related to specific circumstances, such as reactor genmetry, transprort of the substances and the reactions on the growing surface as well as in the gas phase In case of AI. D the precursors and the growth conditions are chosen 10 accold to self-limites growth. Procursors react only with the substance adsorbed on the solid surface during the exposure of the growing film to the other precursor, and cannot be deposited more than ons monolayer diung every reaction step. For this reason the adsorption process can be described more cxally and the dat a concerning with the surface reactions shouk be more reliable in case of $\mathrm{AI}$ D rather than in case of conventional CVD. 
However, the theoretical model has to be fitted with geometry af reactor uscel for experimenial research.

It has been shown that channel-type ALD reactors have some aclvantages in investigation of growth kinetics $[17,18]$. Therefore, a calculation model lo describe the ALD growth in this type of reactor is presented below. The model is used to study the propagation and adsorption of a precursor. The effect of the carricr gas flow rate, sticking and diffusion coefficicnts of the precursor and reactor temperature on the length and formation rate of the steady-state adsorption wave is investigated. Finally, surfacc coverage of the substrates and mean values of precursor concentration as the parametcrs available from experiments are calculated for different growth conditions.

\section{THEORETICAL}

We consider the ALD growth in a low-pressure gas-transport reactor where substrates are litcated parallel to one another and to the gas How direction whereas the distance between the substrates is small compared with the width of the substrales (Fig. 1). Continuous flow of carrice gas passes through the reactor and the both precursors are added to that alternatively. In order to prevent gas phase reactions the reactor is purged from the surplus of the reactants by pure carrier gas flow between subsequent reactant pulses. The gas flow is assumed to be viscous and laminar.
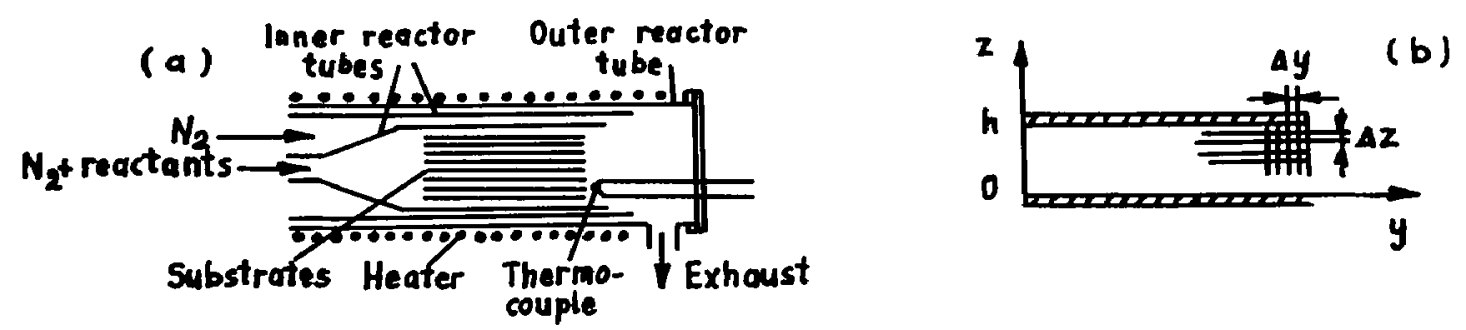

Figure 1: Schematic diagram of the AII) reactor (a) and a channel between two substrates (b).

Carrier gas flow rate, total pressure and temperature in the channels between the substrates are assumed to be constant. Varintion of the precursor concentration, o (in moles per unit vol. ume), is described by the continuity equation

$$
\frac{\partial c}{\partial t}+\operatorname{div} \vec{N}=R
$$

where $\vec{N}$ is the molar flux of the precursol, i.c. the number of moles passing through unit area per time unit, and $R$ is the number of moles emitted in unit volume per time unit. When diffusion of the precursor in the carrier gas is taken into account, the following relationship can be written for $\dot{N}$, 


$$
\vec{N}=\frac{c}{c+c_{r}}\left(\vec{N}+\vec{N}_{r}\right)-\left(c+c_{r}\right) \operatorname{lograd}\left(-\frac{c}{c+c_{r}}\right),
$$

where $\vec{N}_{c}$ and $c_{c}$ arc the flux and the concentration of the carricr gas, respectively, and $D$ is the diffusion coefficicnt of the precursor in the carric gas. Assuming that $c_{c}$ is constant and $c \ll c_{c}$, and taking into account that $\ddot{N}_{c}=\ddot{i}:$ where $v$ is the velocity of the carrier gas, Eq.(2) gives

$$
\vec{N}=c \vec{v}-D \operatorname{grad} c
$$

We also assume that the distance between the substrates, $h$ (Fig. Ib) is small compared to the width of the substrates. Therefore, Lwo-dimensional case is considered in the following. Using Eq.(3), Eq.(1) obtains the form

$$
\frac{\partial c}{\partial t}+v \frac{\partial c}{\partial y}-D\left(\frac{\partial^{2} c}{\partial y^{2}}-\frac{\partial^{2} c}{\partial z^{2}}\right)=R .
$$

where $v$ denotes the $y$-iomponent of $\ddot{v}$. Since the gas. flow is viscous, $v$ depends on the value of z. This velocity dependence may be expressed through the mean flow rate $\bar{v}$ as

$$
v=6 \bar{v}\left[\frac{z}{h}-\left(\frac{z}{h}\right)^{2}\right] \text {. }
$$

When the adsorption on the channel walls is self-limited, as it is inherent to ALD, the surface coverage, $\Theta$, can be calculated from the relationship

$$
\frac{\mathrm{d} \Theta}{\mathrm{d} t}=\frac{k(1-\Theta)<v>c}{4 N_{0}}-\frac{\Theta}{\tau} .
$$

where $k$ is the slicking cocficient, $\langle v\rangle$ is the mean thermal velocity of precursor molecules, $N_{n}$ is the density of adsorption sitcs on the growing surlace and $r$ is the desorption rate constant. Further the desorption rate is assumed to be small, so that the second term on the right side of Eq.(6) is neglected in the following considerations.

We assume that at $t=0$ the surface coverage of the sulstrales and precursor concentration are equal to zero cverywhere in the channel, white concentration is assumed to be equal to in at the inlet of the channel where $y=0$ ). Precursor concentration is assumed to retain the value $c_{n}$ at the channel inlet cluring the pulse. Eq.-s (4) and (6) are used to determine $c$ in the channel and $\Theta$ for next time moments. To solve Eq.-s (4) and (6), the channel is divided into small parts, as shown in Fig. 1 b, and $c$ and its derivatives, as well as variation of $\Theta$ are calculated for all these parts at time moments separated by sufficiently small time intervals.

It is taken into account that adsorption is the reason for precursor molecules to leave the gas phase and it takes place in the rectangles adjacnt to the channel walls. In these rectangles,

$$
R=-\frac{N_{0}}{\Delta z} \frac{\mathrm{d} \Theta}{\mathrm{d} /}
$$

while $R=0$ in the other restangles. 


\section{CALCULATION RESULTS AND DISCUSGION}

Some facilities of the model calculations are demonstrated below. It is shown how a steady-state adsorption wave is formed between the substrates and how this process depends on the sticking and diffusion coefficients of the precursor, on the mean flow rate of the carrier gas and on reactor temperature.

Besides the surface coverage, the precursor concentration is averaged over the distance between the substrates is under consideration.

\subsection{Formation of a steady-state adsorption wave}

Time dependence of $\Theta$ and $\bar{c}$ calculated for definite growlh parameters and certain values of $y$ is demonstrated in Fig. 2.
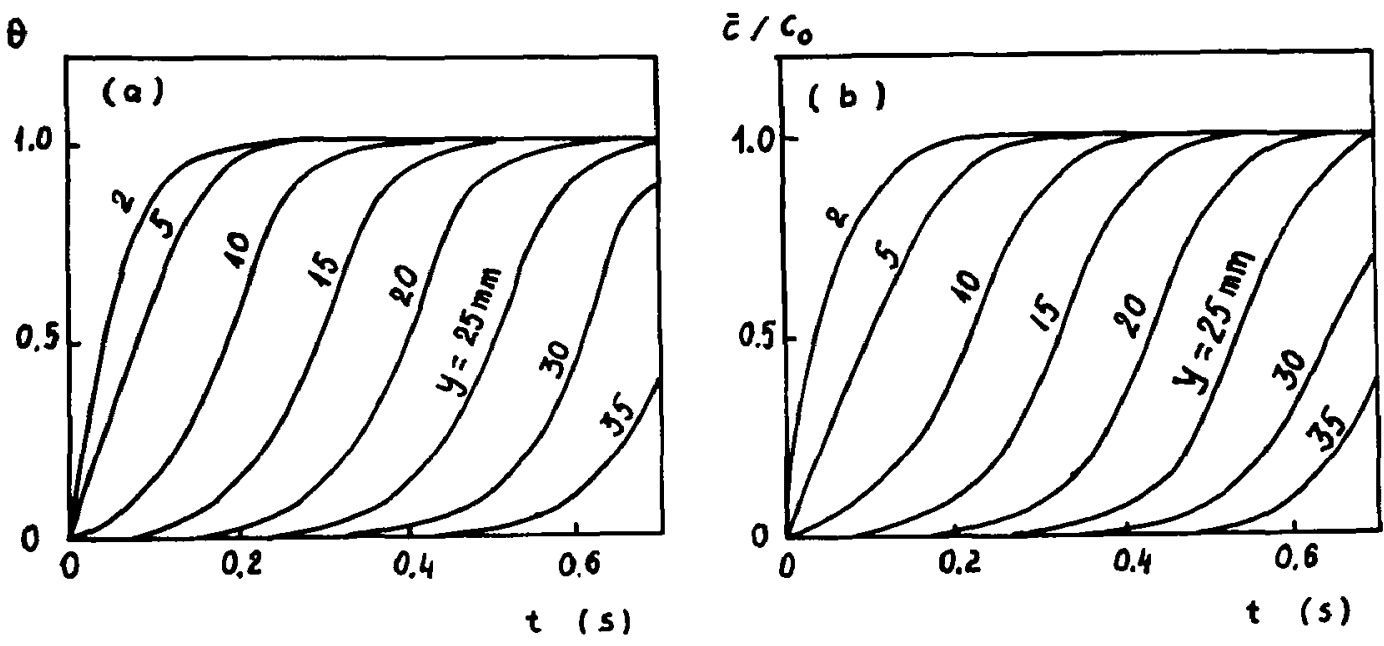

Figure 2: 'Time dependence of the surface coscrage, $(-)$, (a), aut if the anceraged relative precursor concentration, $\left.\bar{c} / c_{n},(b) . \quad \bar{v}=20 \mathrm{~m} / \mathrm{s}, l\right)=0.03 \mathrm{~m}^{2} / \mathrm{s}, k=0.1, h=24 \mathrm{~mm} .<., \cdots:=6410 \mathrm{~m} / \mathrm{s}, c_{0} / \mathrm{N}_{\mathrm{n}}=2 \mathrm{~m}^{-1}$.

As one can see, $\Theta$ and $\vec{b}$ increase mislly near the chand inlet at the beginning of the puisc. Simultaneously the propagation ra:c of the precursot slow': lown until a region with a stable concentration profile (stcady-state concentration wave) is inrmed. A certain surface coverage profile corresponds to cvery concentration profile and they bolh move with the same (constant) rate towards the reactor outlet when the formation of steady-state profiles is completed.

The effect of the growth parameters on the propagation rate of the steady-state adsorption wave was a nalyzed in our previous parer [18] while the ellect of $\bar{v}, k$ and $D$ on the length and formation time of that will be discussed below. In order to characterize the initial stage of propagating the adsorption wave we calculated the time $f^{3}$ recessary to ohtain the surface cov-

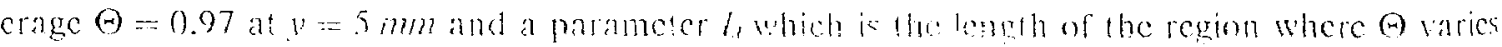


from 0.9 to 0.1 . The dependence rif $t^{*}$ and $l_{d}$ on $k$ and $\vec{i}$ is presented in Figs. 3 and 4 , respeclively, for (ww valucs of $[$ ).

$t^{*}(s)$

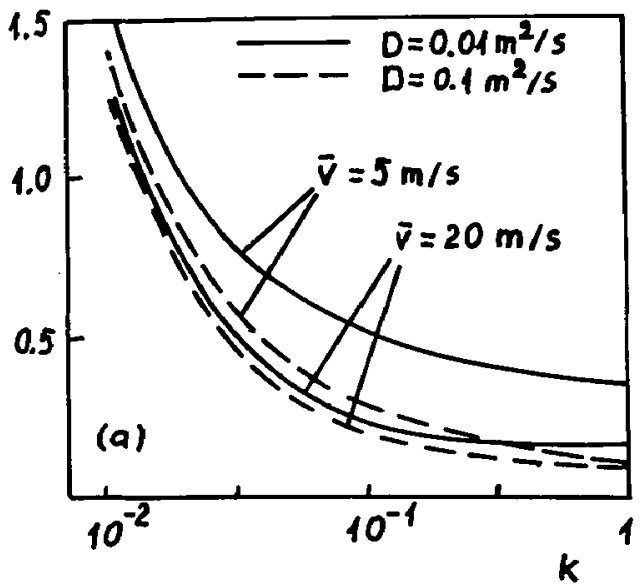

$(d)(m m)$

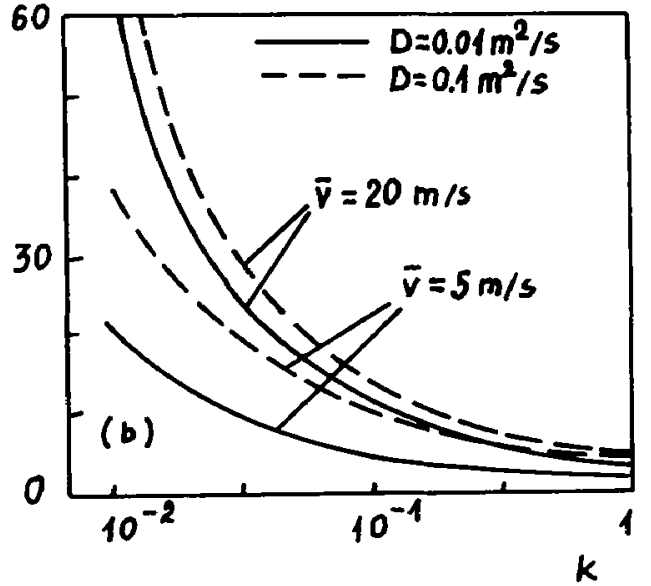

Figure 3: Formation time, $t^{*},\left(\right.$ a) and length, $I_{s}$ (b) of stcety-state alsopption wate as functions of sticking coefficient, k. $h=2.4 \mathrm{~mm}, \quad\langle v\rangle=6.4(1) \mathrm{m} / \mathrm{s}, \quad r_{n} / \mathrm{k}_{\mathrm{n}}=2 \mathrm{~m}$ !
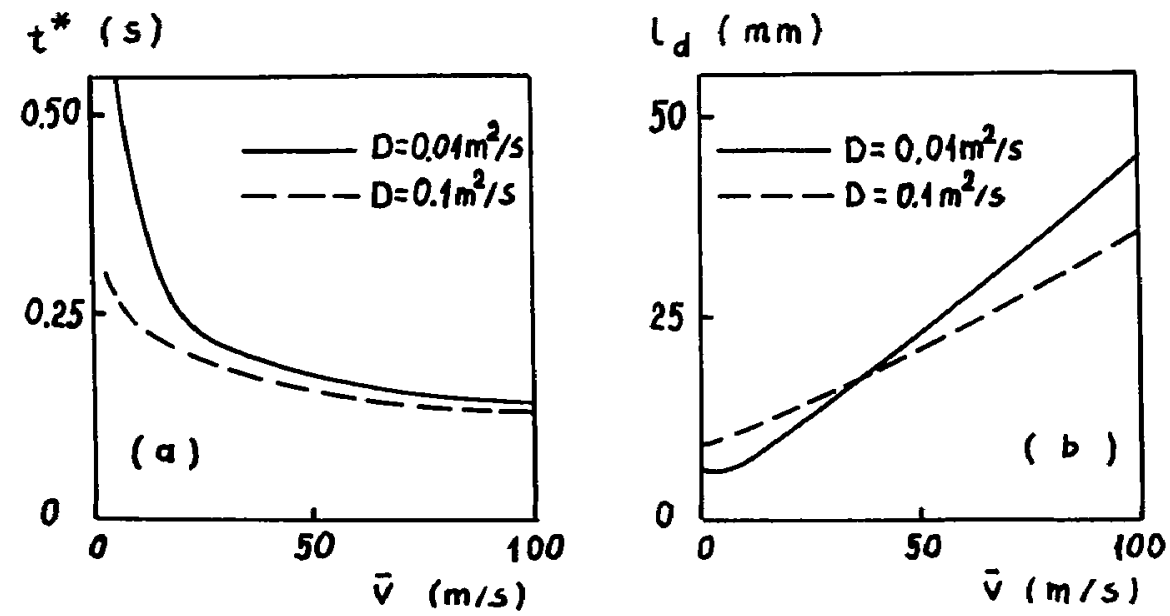

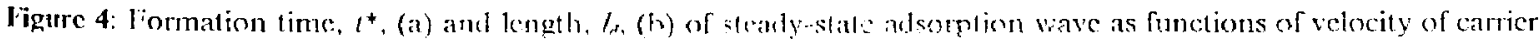

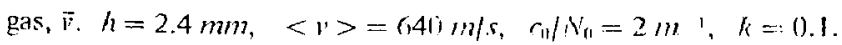

Although the propagation rate of the steady-stale adsorption wave is almost independent of $k$ $[18], t^{*}$ and $l_{d}$ both increase mpidly with decrasing $l$. . This result shows that less than a complete monolayer of the comprount grews per eyele if the pulse lime is too short white the film

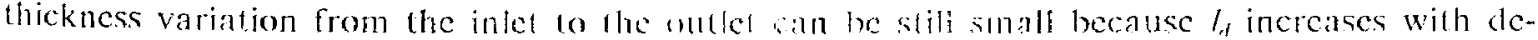

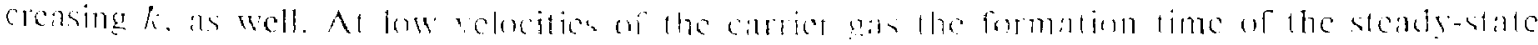

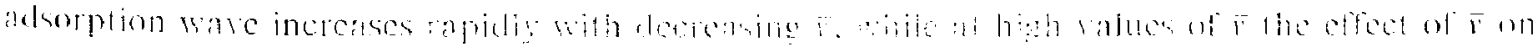


$t^{*}$ is weak. At the same time ${ }^{\prime}$ increases with $\bar{F}$. As me can see in Fig. 4, the longitudinal diffusion is significant at low velocilies ol the carrice gas white the values of $l_{d}$ are higher and the steady-slate adsorption wave is formed fister at higher $D$ valuce. Lower $l_{d}$ corresponds to high D) at high $\bar{y}$ showing that transwersal diffusion plays sume role in this region. This effect increases with increasing distance between the substrates. The calculalions show that at low $\bar{p}$ the surface coverage reaches the value 0.97 remalikably faster 1 hinn $\bar{c} / r_{n}$, but at high velocities it occurs on the contrary. Consequenlly, the precursor is blown lhough the channel even when the surface coverage is still rather low.

\subsection{Effect of temperature}

It is obvious that the sticking and diffusion coefficienls as well as the thermal velocity of precursor molecules depend on temperature. However, it is ather difficult to predict the effect of temperature on the sticking coefficient hecause the mechanisme of surface reactions can be very different at different temperatures. Thus, we concern with the effects caused by temperature dependence of $<v>$ and $D$,

$$
\begin{aligned}
& <v>=v_{0}\left(T / T_{0}\right)^{1 / 2}, \\
& \left.D==D_{0}\left(T / T_{0}\right)\right)^{3 / 2},
\end{aligned}
$$

where $v_{0}, D_{0}$ and $T_{0}$ are constants. To study the temperature dependence, their values were

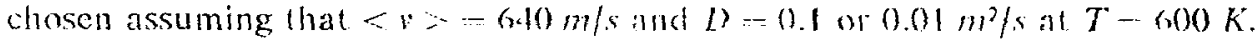

First, the coverage profile was calculated for differcat temperitures at the same time moment (Fig. 5).
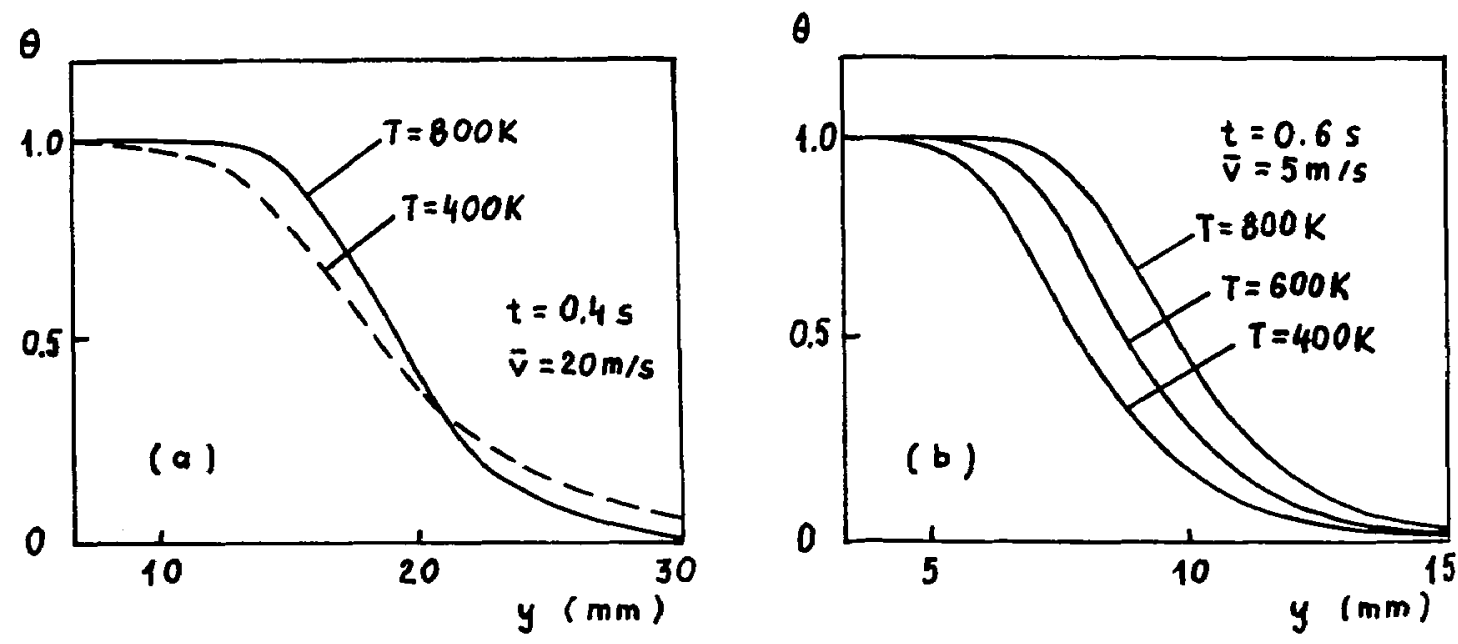

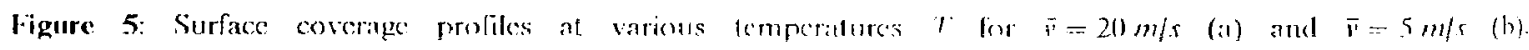
$k=0.1, h=2.4 \mathrm{~mm}, \quad c_{n} / N_{r}=2(i, .21$. 
We can see that temperature affects the propagation rate of the precorser at hew values of $\bar{v}$ when increase of the longitudinal diffusion rate acompanies the lemperature increase. At high ir longitudinal diffesion and femperature

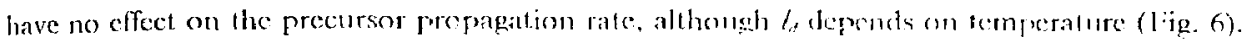
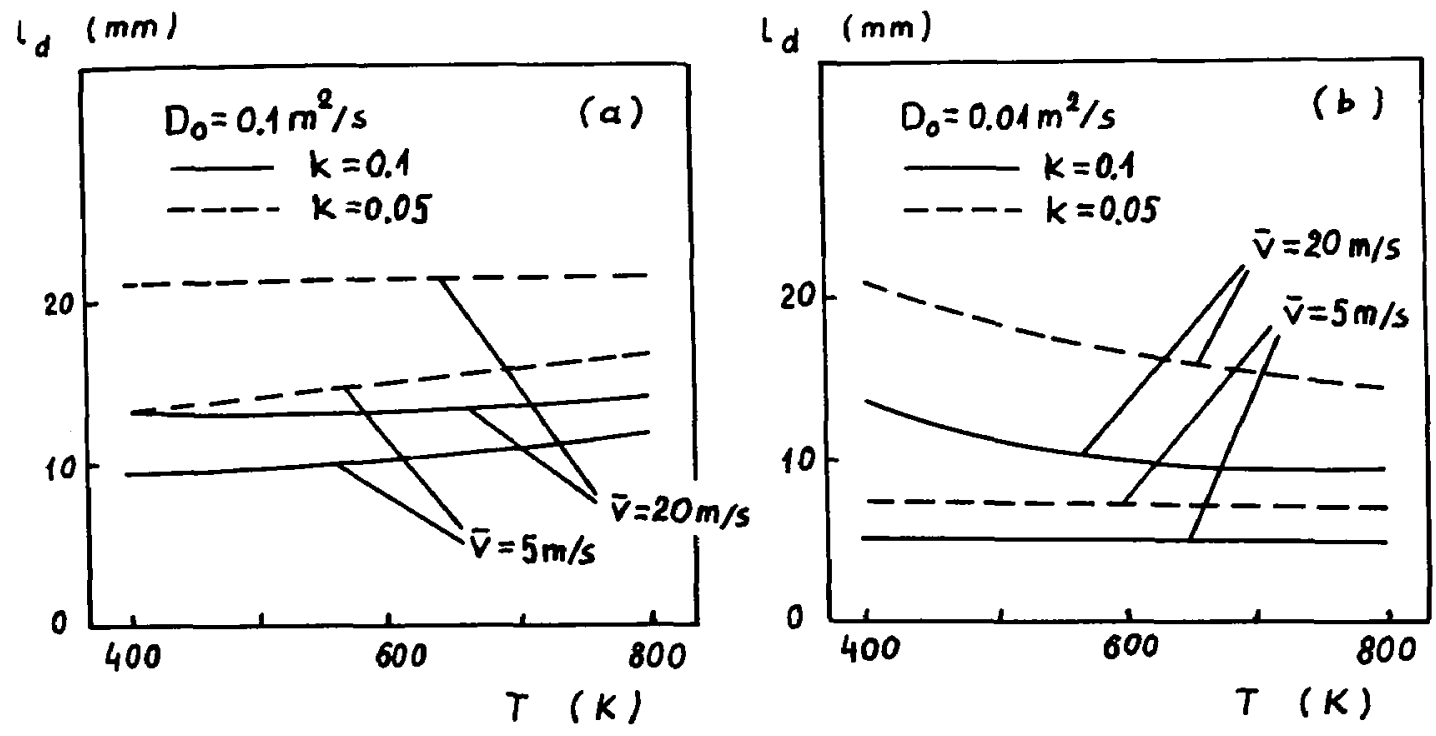

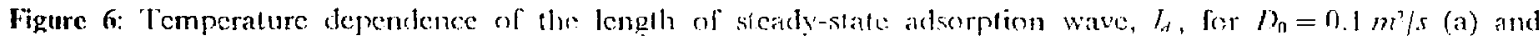
$D_{n}=0.01 \mathrm{~m}^{2} / \mathrm{s}(\mathrm{h}) . \quad h=2.4 \mathrm{~mm}$.

It is interesting that the temperature dependence of $I_{d}$ is essentially effected by $D$. At sufficiently high values of $D$, the increase of $l_{d}$ with $T$ is caused by incrcasing longitudinal diffusion which has particular importance in case of low $\bar{v}$. At low values of $l$ ). $l_{d}$ decreases with increasing temperature. This behavior may be calused by two circumstances. First, increase of $D$, with incrcasing $T$ causes increase of transversal difrusion and, scondly, mean thermal velocity $<v>$ increases with $T$. The both effects are remarkable at high flow rates. In general, the effect of temperature on $l_{d}$ is stronger at lower sticking confricients.

\section{CONCLUSIONS}

Our calculations show that surface coverage profile and, consequently, the thickness profile of the growing film depend significantly on difrusion and sticking coefricients of precursor molecules, flow rate of carrice gas and reactor temperature. Bomb, the formation time of the steadystate profile and the lenglt of this profile increase signilicantly with decreasing sticking coefficient. Therefore rather uniform films can be grown using insufficient precursor doses at high flow rates of the carricr gas. As a result on unambiguous information about the sclf-limi-

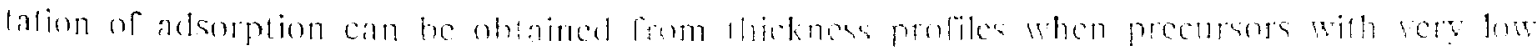
sticking cosficient are uscel. 
Our calculations also demonstrate that the behavior of surface coverage profile with changing temperature depends significantly on the flow rate of the carricr gas, gas phase diffusivity of precursor molecules and distance between the substrates. The length of nonuniform thickness profile increases with increasing temperature at low values of $i$ and high values of $D$ while that (lecreases with increasing temperature at high values of $\bar{v}$ and low values of $D$. This phenomenon can be explained by different contributions of cliffusion and thermal motion of gas molccules to the adsorption process and propagation of the adsorplion wave.

\section{Acknowledgements}

The authors are thankful to Tect Uustare for critical reacling of this paper. This work was supported by Estonian Science Foundation (Grant No. 1.330).

\section{References}

[1] Aspnes D.E., IEEE J. Quant. Electron. 25 (1989) 10.56-1063.

[2] Yamauchi Y., Kobayashi N. and Horikoshi Y'.. Jpn. I. Appl. Phys. 30 (1991) L918-L920.

[3] Koukitu A., Ikeda H., Suzuki H. and Scki H., Ipn. J. Appl. Phys. 30 (1991) L_1712-L1714.

[4] Uwai K. and Kobayashi N., Appi. Phys. Loul. 65 (1994) $1.50-152$.

[5] Maa B.Y. and Dapkus P.D., Thin Solid Films 225 (1993) 12-16.

[6] Nishizawa J., Sakuraba H. and Oyama Y., Thin Solid Films 225 (1993) 1-6.

[7] Hyvärinen J., Sonninen M. and Törnqvist R., J. Cryst. Growth 86 (1988) 695-699.

[8] Andricw S., Beck F. and D'A vilaya T.A., Thin Solid Fiims 184 (1990) 85-92.

[9] Romanychev A.I., Diozd V.E. and Aleskovskii V.B., I. Appl. Chem. USSR 62 (1988) 11-14. [10] Fan I.-F. and Toyoda K.. Appl. Surf. Sci. 60/61 (190?) 76.5-769.

[1 1] Aarik J.. Aidla A., Jack A., Leckelï M. and Niini (ii L.., Appl. Surf. Sci. 75 (1994) 33-38.

[12] Koukitu A., Ikeda H., Yasulake H. and Seki H.. Ipn. I. Appl. Phys. 30 (1991) L1847-1.1849.

[13] Couderc J.-P., J. Phys. IV France 3 (1993) 3-16.

[14] Houf W.B., Grcar J.F. and Breiland W.G., Mater. Sci. Eng. B17 (1993) 163-171.

[15] Pons M., Barbier J.N., Bertiad C. and Madar R., Appil. Surf. Sci. 73 (1993) $71-81$.

[16] Rouch H., Pons M., Benezech A., Barbier J.N.. Bernard C and Madar R., J. Phys. IV France 3 (1993) 17-23.

[17] Suntola T., Thin Solid Films 225 (1993) 96-98.

[18] Aarik J. and Simon H., Appl. Surf. Sci. 81 (1994) 281-287. 